\title{
APResentaÇão
}

\section{As múltiplas faCeS de PROBlemas SituAdos SOB O TÓPICO COGNIÇÃo \& LINGUAGEM}

[The MUltiple FACETS OF PROBLEMS UNDER THE TOPIC COGNition \& LANGUAGE]

Nara M. Figueiredo * Universidade Estadual de Campinas, Brasil

$\mathrm{O}$ que observamos ao pesquisar qualquer tópico que se enquadre sob os rótulos Cognição elou Linguagem é a grande diversidade de perspectivas sob as quais podemos considerá-los e de aspectos relevantes sobre os quais devemos nos debruçar. Muitas vezes, durante a pesquisa, esclarecemos alguns pontos muito específicos, algumas vezes obtemos uma visão perspícua e panorâmica sobre um determinado foco de debate, mas sempre temos o objetivo de obter uma visão perspícua e panorâmica ampla o suficiente para iluminar as grandes questões que temos acerca da nossa própria condição humana, enquanto seres linguísticos. Os esforços que venho empenhando vão nessa direção: a de obter uma visão perspícua e panorâmica dos diversos focos de debate que compõem um amplo cenário de compreensão acerca da nossa condição humana.

Neste texto, apresento com entusiasmo as excelentes contribuições de pesquisadores nacionais e internacionais a este volume e delineio algumas conexões entre eles. Eles iluminam pontos específicos muito relevantes para o amplo cenário de pesquisa sobre Cognição \& Linguagem e compõem uma seleção cuidadosa de grande valia a todos os interessados nesses tópicos. Espero que essas contribuições sejam para você, leitor, tão relevantes quanto são para mim.

Em nosso texto de abertura, "The arrival of the Smartest: In favour of a pluralistic account of the evolution of cognition", Giorgio Airoldi, pesquisador e professor da UNED, de Madrid, na Espanha, nos convida a refletir sobre o aspecto evolutivo da cognição e sobre como as concepções cognitivistas tradicionais da mente (representacionalismo e computacionalismo) falham em captar a realidade complexa dos fenômenos cognitivos. Airoldi inicia seu artigo descrevendo um interessante conto de ficção científica no qual a seleção do mais adaptado não equivale à seleção do mais

* Pesquisadora no Centro de Lógica Epistemologia e História da Ciência - CLE, da Universidade Estadual de Campinas - Unicamp. E-mail: naramfigueiredo@gmail.com 
inteligente. A partir disso, ele sugere que desenvolvimentos recentes na biologia evolutiva, que consideram outros fatores além da seleção natural para explicar a evolução, são vantajosos para as recentes teorias da cognição que consideram seu caráter corporificado e situado. Segundo Airoldi, os fenômenos cognitivos envolvem aspectos externos aos agentes cognitivos que são imprescindíveis para nossa compreensão e, por isso, nós temos que "mesclar nossas investigações sobre 'quem é o mais inteligente' e sobre 'de onde ele veio', em uma abordagem unificada." (AIROLDI, 2021, neste volume - tradução livre). Creio que nosso conhecimento sobre os aspectos não adaptativos de processos evolutivos e suas relações com o desenvolvimento de nossas capacidades cognitivas é uma excelente forma de iluminar a natureza dessas capacidades. Recentemente defendi, em parceria Giovanni Rolla, a construção humana do mundo, literalmente. (Cf. FIGUEIREDO \& ROLLA, 2021). Essa construção é, além de material, também social e política, isto é, de ações, relações e interações que se desenvolvem, materialmente, no decorrer do tempo.

Essa ideia - de construção histórica e material do mundo por meio de ações e relações - está claramente explicitada na referência de Camila Moura Pinto à concepção de Gumbrecht (2010) sobre a materialidade da comunicação em processos de significação. Em seu artigo 'A mente estendida além do discurso: a esfera pública virtual como tecnologia cognitiva', Pinto, que é pesquisadora e professora da UEMG, em Passos, Minas Gerais, considera a visão de Gumbrecht como um dos pilares sobre os quais defende uma interessante perspectiva de formação política a partir da rede mundial de computadores enquanto tecnologia cognitiva. A autora considera a internet enquanto tecnologia cognitiva porque ela distribui informação e integra, sob uma perspectiva estendida, nosso sistema cognitivo. A partir disso, Camila sugere que o corpo e suas extensões são agentes do processo de conscientização política. Ela enfatiza que a perspectiva habermasiana de "esfera pública enquanto espaço para atos de fala, discussão de idéias ou mesmo de emancipação social” (PINTO, 2021, neste volume), deve incluir aspectos corporais e tecnológicos da cognição para repensarmos os processos de formação política atual. Pinto conclui sugerindo a urgência de considerarmos a perspectiva epistemológica da esfera pública virtual diante do recente surgimento de "verdades alternativas" que descreditam verdades científicas e intelectualmente eruditas. Precisamos reconhecer, afirma a autora, "que as redes sociais virtuais não são simples ferramentas tecnológicas, mas constitutivas da cognição, [...] transformando a percepção sobre a realidade e impactando a dimensão social e política da cognição".

Em "O emergentismo como alternativa teórica para o problema mente-corpo" Fabiense Pereira Romão mestre pela UFU, em Uberlândia, Minas Gerais, e Leonardo Ferreira Almada, pesquisador e professor da mesma universidade, sugerem que o problema mente-corpo, a saber, a dificuldade de explicar o surgimento de fenômenos mentais a partir de processos físicos, ou, em outras palavras, o problema difícil da consciência (CHALMERS, 1996, 2011), têm um tratamento viável sob uma ótica emergentista. Isso significa dizer que a consciência pode ser explicada por meio de "complexas relações entre as propriedades do sistema ('todo') e de seus componentes ('partes')", que ela "resulta das relações de interação e integração entre cérebro, corpo e ambiente" (ROMÃO \& ALMADA, neste volume) e que depende de uma uma metafísica de processos. A mente consciente é, deste modo, concebida como uma propriedade emergente, sob uma perspectiva não reducionista, não dualista e naturalista. Isto é, não bastam processos cerebrais para explicar processos cognitivos. É preciso explorar as relações e processos que ocorrem entre cérebro, corpo e ambiente para compreender a consciência. 
Considerando mais especificamente as relações entre consciência e ambiente, André Sant'Anna, pesquisador na Universidade de Washington em St. Louis - US, nos oferece uma importante reflexão sobre o aspecto causal da memória de episódios experienciados por nós - a chamada memória episódica. Em seu texto "Mnemonic causation, construction, and the particularity of episodic memory", Santanna considera que a ampla aceitação das teorias causais de memória episódica enquanto uma boa explicação para a particularidade dessas memórias, isto é, para seu caráter único e representativo de eventos específicos, deve ser revista. Segundo ele, a principal razão para essa sugestão é que as explicações causais da memória falham em explicar seu caráter construtivo, isto é, o fato de que muitas memórias episódicas são reconstruções de eventos passados baseadas em experiências e outras informações recombinadas. Sant'anna finaliza sua contribuição sugerindo que considerar o conteúdo das memórias episódicas pode ser uma via promissora para lidar com essa dificuldade. As memórias episódicas, segundo essa proposta, possuiriam conteúdos auto-referenciais (FERNÁNDEZ, 2006; 2019 apud SANT'ANNA, 2021, neste volume), em função de serem memórias de estados mentais causados por eventos passados (Cf. SANT'ANNA, 2020), ao invés de terem sido diretamente causadas por eventos passados.

Ao falarmos sobre o conteúdo dos estados mentais e sobre seu caráter representativo, podemos avaliar a grande relevância das teorias representacionais da cognição. Raquel Krempel, pesquisadora da Unifesp em São Paulo, em seu artigo "The representational theory of mind and common sense psychology" sugere que teorias representacionais e computacionais da mente, também chamadas de cognitivistas, são mais vantajosas do que teorias behavioristas para explicar fenômenos mentais e comportamentos. Segundo ela, isso se deve ao fato de que teorias cognitivistas nos permitem conceber estados mentais preservando sua eficácia causal e sua avaliabilidade semântica. Em outros termos, nos permite manter a ideia de que estados mentais podem causar ações e outros estados mentais, que eles podem ser causados por eventos externos e que eles são sobre aquilo que eles representam. Krempel parte do divertido exemplo de uma moça em busca de cookies em uma padaria e ilustra algumas das dificuldades enfrentadas pelos behavioristas tecendo uma crítica à concepção Wittgensteineana de compreensão linguística. Ela apresenta uma leitura da filosofia da mente de Wittgenstein como advogando pela ausência da necessidade de estados mentais para explicar o sentido, ou significado, das palavras e sentenças na nossa linguagem cotidiana. De fato, Wittgenstein é conhecido por defender que não precisamos fazer referência a estados mentais privados para compreender o significado de uma palavra. Mas as implicações dessa perspectiva para a filosofia da mente são controversas e há bastante desacordo sobre sua interpretação.

Em uma leitura antagônica à de Krempel, Victor Laughlin, pesquisador da Universidade de Antwerp, na Bélgica, em seu texto "Why later Wittgenstein was not a therapist" considera um exemplo similar, o de uma dupla de amigos em uma cafeteria, para sugerir que o significado de uma palavra, por exemplo, 'mind' pode variar consideravelmente conforme o uso. Esse exemplo é apresentado para defender que nosso diálogo cotidiano sobre o mental evidencia problemas filosóficos sobre a natureza da mente de processos mentais. Laughlin considera o caso específico do entendimento, para defender que "esclarecer o que significa entender requer considerarmos circunstâncias particulares" (LAUGHLIN, 2021, neste volume tradução livre) ao invés de considerarmos qualquer processo que possa estar ocorrendo durante a compreensão. Questionando principalmente o propósito da filosofia e a natureza dos problemas filosóficos, Laughlin oferece razões em favor de uma leitura não-pirrônica da filosofia de Wittgenstein. Segundo ele, wittgensteinianos pirrônicos 
defendem que a atividade filosófica é apenas o esclarecimento de confusões conceituais, enquanto wittgensteinianos não-pirrônicos defendem uma filosofia wittgensteiniana positiva que trata de questões dentro dos limites do sentido. Seu objetivo último é o de evidenciar que problemas sobre a natureza da mente são problemas filosóficos - ao invés de confusões conceituais - e que esclarecê-los não envolve descobrir supostos princípios mentais, mas sim, analisar os conturbados cenários nos quais observamos e praticamos ações. Segundo essa leitura, nossa compreensão filosófica sobre estados mentais (entendimento, justificações de ações, crenças, desejos, etc.) é alcançada por meio da observação de circunstâncias específicas nas quais observamos um determinado estado publicamente ao invés de por meio de estados internos.

No texto, "Conceitos goal-derived e a tese da latência semântica", Diogo Gurgel, professor e pesquisador da Universidade Federal Fluminense e Guilherme Soares, mestre pela mesma universidade, no Rio de Janeiro, sugerem que teorias corporificadas da mente que oferecem abordagens multi-modais de conceitos com finalidade específica (ad hoc), somadas à Teoria da Relevância (WILSON \& SPERBER, 1986), nos permitem reabilitar a tese de que algumas inovações semânticas são fragmentos de memórias de experiências de participação em práticas normativas, isto é, fragmentos de memórias de conceitos formados para fins específicos. Gurgel e Soares sugerem inicialmente que uma reformulação da nossa noção de conceito se faz necessária diante de vários fatores na história recente da pesquisa sobre cognição e linguagem: O surgimento do pragmatismo - com a noção de semelhança de família, em Wittgenstein (2009) - a Teoria de Protótipos (ROSCH, 1973, 1978), a psicologia ecológica (GIBSON, 1979/2015), bem como "a crise de uma concepção representacionalista forte que, de acordo com Casanto e Lupyan (2015), caracteriza os conceitos como 'entidades discretas que existem inteiramente formadas, mesmo quando não as estamos usando (...)' (CASANTO; LUPYAN, 2015, p. 544).” (GURGEL \& SOARES, neste volume). A partir de todos esses fatores relevantes, Gurgel e Soares pretendem mostrar que a Teoria de Relevância de Wilson e Sperber (2012) pode ser compatibilizada com o modelo simulacionista de cognição situada de Barsalou (1983, 1991, 2005).

Em algumas reflexões sobre a linguagem, em que o foco não está em compreender a natureza de conceitos, mas a de itens linguísticos, tentamos compreender como palavras e nomes adquirem significado e como termos singulares podem ser definidos. Em nossos textos de encerramento, Marco Ruffino e Ana Clara Polakof se debruçam sobre essas importantes questões do debate em filosofia da linguagem.

Marco Ruffino, pesquisador e professor do Centro de Lógica, Epistemologia e História da Ciência, da Unicamp, em Campinas, em seu texto "Descriptive Reference Fixing and Epistemic Privileges" se ocupa da natureza dos nomes e das descrições, bem como da possibilidade de conhecermos verdades contingentes a priori. Verdades contingentes são aquelas que não são sempre verdadeiras. Verdades a priori, por outro lado, são aquelas que podemos saber sem recorrer à experiência sensível, apenas por meio da razão. A proposta de Kripke (1980) sobre a existência de verdades contingentes a priori consiste, em termos gerais, em mostrar que é possível conhecermos uma verdade independentemente da nossa experiência, mesmo que ela não seja sempre verdadeira. A princípio, essa proposta parece paradoxal, pois verdades que independem da experiência são consideradas, desde Kant (CRP), verdades universais, necessárias, nas quais o predicado está contido no sujeito, e não verdades contingentes. Ruffino oferece uma detalhada argumentação apontando para pontos fortes e fracos da 
argumentação de Donnellan (1977) contra a proposta de Kripke sobre o conteúdo contingente de uma proposição e sugere que tanto a visão de Donnellan quanto a visão de Kripke "estão parcialmente corretas e parcialmente erradas" (RUFFINO, 2021, neste volume - tradução livre). Em seu percurso, Ruffino considera o argumento de Jeshion (2001) contra Donnellan e sugere que há uma segunda lacuna no argumento de Donnellan contra Kripke. Sua proposta é que a concepção de Kripke acerca da existência do conteúdo contingente de uma proposição pode ser mantida, mas apenas nos casos em que o conteúdo de uma proposição pode ser verdadeiro por estipulação.

Em seu texto "A Linguistic Account of Singular Terms" Ana Clara Polakof, professora da FHCE, da UdelaR, e pesquisadora do Sistema Nacional de Investigadores, no Uruguai, considera como podemos reconhecer e definir termos singulares e, para este fim, analisa contextos nos quais eles ocorrem. Sua análise se desenvolve a partir de três hipóteses principais, a saber, de que "um termo singular se enquadra na forma lógica de uma proposição, [...] que pode ser atômico [e que] pode se referir singularmente a um indivíduo" (POLAKOF, 2021, neste volume - tradução livre). Os contextos e as duas primeiras hipóteses são baseadas no que Vendler (1967a, 1967b) defende sobre o reconhecimento de termos singulares. A análise de Polakof mostra que os contextos considerados por Vendler não são suficientes para definir o que é um termo singular porque eles não evidenciam as condições necessárias e suficientes para que uma frase nominal forme um termo singular. Polakof oferece uma visão alternativa para a definição de termos singulares considerando desenvolvimentos do campo da Linguística e sugere que precisamos considerar a interface entre sintática e semântica para oferecer as condições necessárias e suficientes para definirmos um termo singular.

Assim, como podemos observar pelas localidades geográficas de cada um dos participantes deste volume, de Madri na Espanha, à Montevidéu no Uruguai, passando por Belo Horizonte e Uberlândia em Minas Gerais, St. Louis nos Estados Unidos, São Paulo capital, Antwerp na Bélgica, Rio de Janeiro capital e Campinas em São Paulo, vamos conectando pontos e fortalecendo nossas conexões em uma rede complexa e plural de interações humanas que visam um fim comum: compreender a nós mesmos e às nossas práticas.

\section{Agradecimentos}

Primeiramente, gostaria de agradecer a todos os autores que depositaram confiança na proposta deste volume e se dispuseram a enviar seus trabalhos. Meus cumprimentos especiais aos autores dos textos selecionados.

Saudações e agradecimentos aos muitos pareceristas que se dedicaram a oferecer sugestões e reflexões primorosas para a seleção dos artigos aqui publicados. E também ao Prof. Dr. César Meurer, da UFABC, em São Bernardo do Campo, pelo apoio em várias fases do processo editorial.

Meus sinceros agradecimentos ao Prof. Dr. Betto Leite, editor chefe da revista Aufklärung, da UFPB, em João Pessoa, que se dispôs prontamente a acolher o projeto, a oferecer todo o apoio necessário para a sua execução e depositou enorme confiança em meu trabalho desde o princípio.

Agradeço também ao apoio do Centro de Lógica, Epistemologia e História da Ciência (CLE), da Unicamp, no qual sou pesquisadora, e também ao financiamento de 
pesquisa do CNPq, sem o qual este trabalho editorial não teria sido possível.

Desejo que você, leitor, tenha uma ótima experiência ao acessar esse conteúdo. Que ele contribua para suas reflexões e para o fomento do debate filosófico e interdisciplinar sobre os tópicos específicos abordados aqui, bem como com o seu empenho em obter respostas para muitas das nossas questões sobre a mente e as práticas humanas.

Nara M. Figueiredo (Unicamp) Editora convidada

\section{REFERÊNCIAS}

BARSALOU, L.W. Ad hoc categories. Memory \& Cognition, v.11, n.3, p. 211-227, 1983.

BARSALOU, L.W. Deriving categories to achieve goals. The psychology of learning and motivation, v. 27, p. 1-64, 1991.

BARSALOU, L.W. Situated conceptualization. In: COHEN, H.C.; LEFEBVRE, C. (ed.) Handbook of Categorization in Cognitive Science. Amsterdam: Elsevier, 2005. p. 619636.

CHALMERS, D. J. The problem of consciousness. Discusiones Filosóficas. v. 19, p. 29-59, 2012.

DONNELLAN, K. S. The contingent a priori and rigid designators. Midwest Studies in Philosophy, 2(1):12-27. 1977.

FERNÁNDEZ, J. Memory: A Self-Referential Account. Oxford University Press, 2019.

GIBSON, J. J. The Ecological Approach to Visual Perception. New York: Psychology Press, 2015.

GUMBRECHT, H. U. Produção de presença: o que o sentido não consegue transmitir. Trad: Ana Isabel Soares. Rio de Janeiro: Contraponto; Editora PUC-Rio, 206p, 2010

JESHION, R. Donnellan on Neptune. Philosophy and Phenomenological Research, 63(1):111-135, 2001.

KANT, I. Crítica da razão pura. 5.ed. Tradução de M. P. dos Santos e A. F. Morujão. Lisboa: Fundação Calouste Gulbenkian, 2001.

KRIPKE, S. Naming and Necessity. Harvard University Press, 1980.

SANT'ANNA, A. The hybrid contents of memory. Synthese, v. 197, p.1263-1290, 2020.

ROLLA, G.; FIGUEIREDO, N. M. Bringing forth a world, literally. Phenomenology and the Cognitive Sciences, 2021 (em edição)..

ROSCH, E. H. Natural Categories. Cognitive Psychology, n. 4, p. 328-350, 1973.

ROSCH, E. H. Principles of Categorization. In: ROSCH, ELEANOR AND LLOYD BARBARA (eds.). Cognition and Categorization, Hillsdale, NJ: Lawrence Erlbaum, 1978. p. 27-48.

WILSON, D.; SPERBER, D. Meaning and Relevance. New York: Cambridge University Press, 2012.

WITTGENSTEIN, L. Philosophical Investigations. G.M.Anscombe, P.M.S.Hacker and J.Schulte (trs). Oxford: Wiley-Blackwell. 2009. 